\title{
Scheduling in A Single-Stage, Multi-Item Compatible Process Using Multiple ARC Network Model and Excel Solver
}

\author{
Dr. IBRAHIM ABDULLAH ALJASSER \\ Associate Professor, MMIS Program Director, College of Business \\ Dar Al Uloom University, Riyadh, Kingdom of Saudi Arabia \\ Email: i.aljasser@dau.edu.sa, iaaljasser@hotmail.com \\ Dr. BOKKASAM SASIDHAR \\ Professor, College of Business Administration \\ King Saud University, Riyadh, Kingdom of Saudi Arabia \\ Email: bokkasamsasidhar@gmail.com, bbokkasam@ksu.edu.sa
}

\begin{abstract}
In the present competitive business environment, a more customer driven approach to production scheduling is required. The criteria considered for production scheduling objectives are generally derived from some desired production performance factors of a manufacturing system. Generally, the customers' orders are categorized as either normal or prioritized based on the delivery requirements. The production is planned against customers' orders, keeping in mind the customers' priorities. The problem of scheduling a given set of machines in a single-stage, multi-item compatible environment, with the objective of maximizing capacity utilization has been formulated (Bokkasam, 2016) as a maximal flow problem in a Multiple Arc Network (MAN). The model provides optimal production schedule with an objective of maximizing capacity utilization, so that the customer-wise delivery schedules are fulfilled, keeping in view the priorities of the customers. The results of a working implementation of the MAN model using excel solver are presented in this paper. The same has been validated with results obtained using two examples. In future the managers will be able to use the worksheet for obtaining the results immediately, for scaledup scenarios.
\end{abstract}

Keywords: Scheduling, Maximal Flow Problem, Multiple Arc Network Model, Optimization, Excel Solver.

\section{Introduction}

In the past decade, a large number of optimization models and approaches have been proposed for batch scheduling and planning. A number of reviews on the planning and scheduling of batch processes have been presented in the literature (Pinto and Grossmann, 1998; Kallrath, 2002; Floudas and Lin, 2004; Burkard and Hatzl, 2005; Mendez et. al, 2006; Pan et. al, 2009).

A decision support system for production planning has been presented by Gunter Schmidt (Gunter Schmidt, 1992; 1996). Considering decision support system as a tool where executive's judgment can be included along with the mathematical tool kit of the management scientist, the need to include problem management as an integral component of the decision support system for scheduling problems have been highlighted (Klaus Ecker et. al, 1997). Decision networks, which involve a sequence of decisions, is gaining popularity among the management scientists (Saksena, 1982; 1985). The problem of scheduling a single-stage multiproduct batch chemical process with fixed batch sizes was presented (Maged and Brian, 1997) as a mixed- 
integer nonlinear programming model to determine the schedule of batches, the batch size, and the number of overtime shifts that satisfy the demand at minimum cost for this process. Shashank et. al (2012) considered scheduling of a multi-item single stage production-inventory system in the presence of uncertainty regarding demand patterns, production times and switchover times.

Optimal scheduling of a set of orders in a multi-product batch plant with non-identical parallel processing units where the process is single stage is presented by Ridvan et.al (2007). The allocation of orders to the production units was formulated as an mixed integer linear programming problem in continuous time. The short-term scheduling of a single-stage batch edible-oil deodorizer that can process multiple products in several product groups is considered by Songsong et. al (2010). Sequence-dependent changeovers occur when switching from one product group to another. Based on the incorporation of products into product groups, mixed integer linear programming models were proposed for two scenarios, with and without backlogs.

A stochastic production planning model for a multi-period, multi-product system, where the lead time to produce a product may be random is developed by Steven Hackman et. al (2002). A comparative study of algorithms for the flow shop scheduling problem is presented by Shiqiang Liu and Ong (2002). The problem of allocating the limited capital resources to the various stages of a multistage production system, in order to improve the yield of the production stages and, at the same time minimize the annual cost is considered by George and Andreas (2003). A heuristic procedure to derive non-permutation schedules from a given permutation schedule is given by Pugazhendhi et.al (2003). The application of artificial neural networks to the problem of job shop scheduling with a scope of a deterministic time-varying demand pattern over a fixed planning horizon is given in Shan Feng et.al (2003).

Since the pioneering work of Ford and Fulkerson (2010) in 1962, the use of network models and algorithms have proved to be particularly successful in different application areas. A Multiple Arc Network (MAN) model of production planning in a steel mill is presented by Sasidhar \& Achary (1991). A MAN model for production planning in a single-stage, multi-item compatible processing environment, which provides an optimal production plan, with the objective of maximizing the capacity utilization has been presented by Bokkasam (2016). This paper presents the application of excel solver in maximizing the capacity utilization of the MAN model, assuming that the benefits of executing priority orders surpass the cost of equipment setup. The cases where the order books are full as well as when order books are not full have been considered, so that the managers will be able to use the worksheet for obtaining the results for scheduling and also that of spare capacity, for scaled-up scenarios.

\section{Scheduling Procedure Using Excel Solver}

As described in Bokkasam (2016), the PROCESSNET is represented by the MAN N=(s,t,V,A,b) with $\mathrm{v}=|\mathrm{V}|$ vertices, representing the equipments and products. The arcs of A include all possible customer-wise orders and all possible products that can be processed on equipments. The procedure for planning and scheduling consists of the sequential applications of excel solver, using the notations in Bokkasam (2016).

\section{Step 1:}

Consider the PROCESSNET with single directed arcs (with arc number $i=1$ ). Maximize the flow along the network by considering the problem as one of linear programming models. Define the capacities along the arcs as follows:

Set $\mathrm{i}=1$

$\mathrm{b}\left(\mathrm{s}, 1, \mathrm{~S}_{\mathrm{k}}\right)=\mathrm{D}_{\mathrm{k} 1}$

$\mathrm{b}\left(\mathrm{S}_{\mathrm{k}}, 1, \mathrm{E}_{\mathrm{r}}\right)=\mathrm{A}_{\mathrm{kr}}$

For all other $(\mathrm{x}, \mathrm{y}) \varepsilon \mathrm{N}, \mathrm{b}(\mathrm{x}, \mathrm{y})=\infty$.

Solve the problem using excel solver and determine the optimal flow. 


\section{Step 2:}

Set $\mathrm{i}=2$

$\mathrm{b}\left(\mathrm{s}, 2, \mathrm{~S}_{\mathrm{k}}\right)=\mathrm{D}_{\mathrm{k} 2}$

$\mathrm{b}\left(\mathrm{S}_{\mathrm{k}}, 2, \mathrm{E}_{\mathrm{r}}\right)=\operatorname{Min} .\left[\mathrm{A}_{\mathrm{kr}}, \mathrm{A}_{\mathrm{kr}}-\right.$ optimum flow along $\left(\mathrm{S}_{\mathrm{k}}, \mathrm{E}_{\mathrm{r}}\right)$ in Step1]

For all other $(\mathrm{x}, \mathrm{y}) \varepsilon \mathrm{N}, \mathrm{b}(\mathrm{x}, \mathrm{y})=\infty$.

Solve the problem using excel solver and determine the optimal flow.

The optimal scheduling is obtained by considering the optimal flows obtained in Step 1 and Step 2 for the prioritized and normal customer orders respectively.

The procedure also provides the machine-wise spare capacities whenever the order books are not full. Further, in case the order books are full, the optimal quantities to be supplied to the customers and the corresponding unfulfilled demands are also brought out.

\section{Illustrative Examples}

Application of the above procedure, using excel solver, is illustrated using two examples. Example 1 considers a simple situation of scheduling a workshop with two machines and three products, where each machine has equal capacity for each product and when the order books are full. The second example demonstrates the applicability of the procedure for a slightly bigger problem, using three machines and five products, where the machines have different capacities for different products and when the order books are not full. In general, the procedure is applicable for situations with any number of machines and products.

\section{Example 1: 2 Machines and 3 Products (Scheduling when order books are full)}

Consider a workshop having two similar lathes $\mathrm{E}_{1}$ and $\mathrm{E}_{2}$ which are being used for manufacturing three types of roller sets $S_{1}, S_{2}$ and $S_{3}$. Assume that both the lathes are capable of manufacturing any of the products and the capacity of each of the lathes $\left(\mathrm{A}_{\mathrm{kr}}\right)$ is 400 units for each of the product. Consider the order position for priority orders and normal orders for the three roller sets $S_{1}, S_{2}$ and $S_{3}$ to be as shown in Table 1.

Note that changeover for handling one type of roller to the other type incurs certain time and associated costs. Since the changeover costs increase with the number of set ups, to minimize the costs associated with the set ups, similar types of products should be processed successively so that the total number of changeovers are minimized. This problem is equivalent to the problem of maximizing the total capacity utilization.

This example illustrates the steps in scheduling the workshop.

Table 1: Order position and priorities for Example 1

\begin{tabular}{|cccc|}
\hline Order Type/Product & $S_{1}$ & $S_{2}$ & $S_{3}$ \\
\hline Priority & 600 & 500 & 300 \\
Normal & 400 & 300 & 700 \\
\hline
\end{tabular}

The PROCESSNET for the workshop is as shown in Figure 1. 


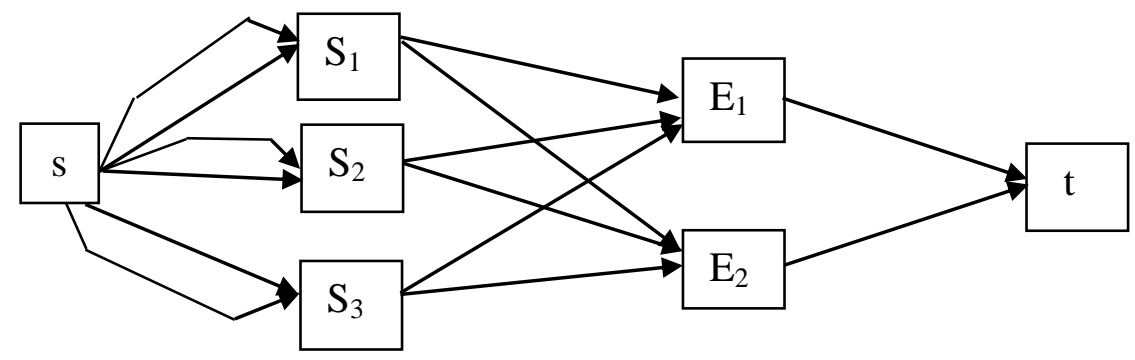

Figure 1: PROCESSNET for the Workshop of Example 1.

Step 1: Consider the PROCESSNET with single directed arcs (with arc number $\mathrm{i}=1$ ).

The demand Dki for the product $S_{k}$ by Order type i will be as follows:

$\mathrm{D}_{11}=600, \mathrm{D}_{12}=400, \mathrm{D}_{21}=500, \mathrm{D}_{22}=300, \mathrm{D}_{31}=300$ and $\mathrm{D}_{32}=700$.

The capacity along the arc from $\mathrm{s}$ to $\mathrm{S}_{\mathrm{k}}(\mathrm{k}=1,2,3)$ is the order quantity Dki for the product $\mathrm{S}_{\mathrm{k}}$ by the order type $i=1$, viz., $D_{11}=600, D_{21}=500$, and $D_{31}=300$ respectively. The capacity of the $\operatorname{arc}\left(S_{k}, E_{r}\right)$ is considered as $A_{k r}$ which is the capacity of processing product $S_{k}$ by equipment $E_{r}$. The capacities of the arcs $\left(E_{r}, t\right)$ are considered as infinity in this example, it is considered as 10000000.

The excel formulation of the problem is shown in Table 2.

Table 2: Excel formulation of Step 1 of Example 1.

\begin{tabular}{|c|c|c|c|c|c|c|c|c|c|}
\hline From & To & Flow & & Capacity & & Nodes & Net Flow & & Supply/Demand \\
\hline $\mathrm{s}$ & $\mathrm{s} 1$ & 0 & $<=$ & 600 & & $\mathrm{~s}$ & 0 & & \\
\hline $\mathrm{s}$ & $\mathrm{s} 2$ & 0 & $<=$ & 500 & & $\mathrm{~s} 1$ & 0 & $=$ & 0 \\
\hline $\mathrm{s}$ & $\mathrm{s} 3$ & 0 & $<=$ & 300 & & $\mathrm{~s} 2$ & 0 & $=$ & 0 \\
\hline $\mathrm{s} 1$ & $\mathrm{E} 1$ & 0 & $<=$ & 400 & & $\mathrm{~s} 3$ & 0 & $=$ & 0 \\
\hline $\mathrm{s} 1$ & $\mathrm{E} 2$ & 0 & $<=$ & 400 & & $\mathrm{E} 1$ & 0 & $=$ & 0 \\
\hline $\mathrm{s} 2$ & $\mathrm{E} 1$ & 0 & $<=$ & 400 & $\mathrm{E} 2$ & 0 & $=$ & 0 \\
\hline $\mathrm{s} 2$ & $\mathrm{E} 2$ & 0 & $<=$ & 400 & & $\mathrm{t}$ & 0 & & \\
\hline $\mathrm{s} 3$ & $\mathrm{E} 1$ & 0 & $<=$ & 400 & & & & & \\
\hline $\mathrm{s} 3$ & $\mathrm{E} 2$ & 0 & $<=$ & 400 & & & & & \\
\hline $\mathrm{E} 1$ & $\mathrm{t}$ & 0 & $<=$ & 10000000 & & & & \\
\hline E2 & $\mathrm{t}$ & 0 & $<=$ & 10000000 & & & & & \\
\hline Max. & & & & & & & & & \\
Flow & 0 & & & & & & & & \\
\hline
\end{tabular}

Using excel solver, the maximal flow as shown in Table 3 is obtained.

Table 3: Solver solution of Step 1 of Example 1.

\begin{tabular}{|cccc|}
\hline Variable Cells & & & \\
\hline Cell & Name & Original Value & Final Value \\
\hline \$D\$4 & s1 Flow & 0 & 600 \\
\hline \$D\$5 & s2 Flow & 0 & 500 \\
\hline \$D\$6 & s3 Flow & 0 & 300 \\
\hline \$D\$7 & E1 Flow & 0 & 400 \\
\hline
\end{tabular}




\begin{tabular}{|cccc|}
\hline \$D\$8 & E2 Flow & 0 & 200 \\
\hline \$D\$9 & E1 Flow & 0 & 400 \\
\hline \$D\$10 & E2 Flow & 0 & 100 \\
\hline \$D\$11 & E1 Flow & 0 & 0 \\
\hline \$D\$12 & E2 Flow & 0 & 300 \\
\hline \$D \$13 & t Flow & 0 & 800 \\
\hline \$D\$14 & t Flow & 0 & 600 \\
\hline
\end{tabular}

Step 2: Consider the same PROCESSNET with single directed arcs (with arc number $\mathrm{i}=2$ ).

The capacity along the arc from $s$ to $S_{k}(k=1,2,3)$ is the order quantity Dki for the product $S_{k}$ by the order type $i=2$, viz., $D_{12}=400, D_{22}=300$, and $D_{32}=700$ respectively. The capacity of the arc $\left(S_{k}, E_{r}\right)$ is considered as Min. $\left[A_{k r}, A_{k r}-\right.$ optimum flow along $\left(S_{k}, E_{r}\right)$ in Step1]. For example, capacity of the $\operatorname{arc}\left(S_{1}, E_{1}\right)$ is Min. $[400,400-400]=0$. The capacities of the $\operatorname{arcs}\left(E_{r}, t\right)$ are considered as infinity in this example, it is considered as 10000000 .

The excel formulation of the problem is shown in Table 4.

Table 4: Excel formulation of Step 2 of Example 1.

\begin{tabular}{|c|c|c|c|c|c|c|c|c|c|}
\hline From & To & Flow & & Capacity & Nodes & Net Flow & & Supply/Demand \\
\hline $\mathrm{s}$ & $\mathrm{s} 1$ & 0 & $<=$ & 400 & & $\mathrm{~s}$ & 0 & & \\
\hline $\mathrm{s}$ & $\mathrm{s} 2$ & 0 & $<=$ & 300 & & $\mathrm{~s} 1$ & 0 & $=$ & 0 \\
\hline $\mathrm{s}$ & $\mathrm{s} 3$ & 0 & $<=$ & 700 & & $\mathrm{~s} 2$ & 0 & $=$ & 0 \\
\hline $\mathrm{s} 1$ & $\mathrm{E} 1$ & 0 & $<=$ & 0 & & $\mathrm{~s} 3$ & 0 & $=$ & 0 \\
\hline $\mathrm{s} 1$ & $\mathrm{E} 2$ & 0 & $<=$ & 200 & & $\mathrm{E} 1$ & 0 & $=$ & 0 \\
\hline $\mathrm{s} 2$ & $\mathrm{E} 1$ & 0 & $<=$ & 0 & & $\mathrm{E} 2$ & 0 & $=$ & 0 \\
\hline $\mathrm{s} 2$ & $\mathrm{E} 2$ & 0 & $<=$ & 300 & $\mathrm{t}$ & 0 & & \\
\hline $\mathrm{s} 3$ & $\mathrm{E} 1$ & 0 & $<=$ & 400 & & & & & \\
\hline $\mathrm{s} 3$ & $\mathrm{E} 2$ & 0 & $<=$ & 100 & & & & & \\
\hline $\mathrm{E} 1$ & $\mathrm{t}$ & 0 & $<=$ & 10000000 & & & & \\
\hline E2 & $\mathrm{t}$ & 0 & $<=$ & 10000000 & & & & \\
\hline Max. Flow & 0 & & & & & & & & \\
\hline
\end{tabular}

Using excel solver, the following maximal flow as shown in Table 5 is obtained.

Table 5: Solver solution of Step 2 of Example 1.

\begin{tabular}{|c|c|c|c|}
\hline \multicolumn{4}{|c|}{ Variable Cells } \\
\hline Cell & Name & Original Value & Final Value \\
\hline \$D\$4 & s1 Flow & 0 & 200 \\
\hline$\$ D \$ 5$ & s2 Flow & 0 & 300 \\
\hline \$D\$6 & s3 Flow & 0 & 500 \\
\hline \$D\$7 & E1 Flow & 0 & 0 \\
\hline \$D\$8 & E2 Flow & 0 & 200 \\
\hline \$D\$9 & E1 Flow & 0 & 0 \\
\hline$\$ D \$ 10$ & E2 Flow & 0 & 300 \\
\hline \$D\$11 & E1 Flow & 0 & 400 \\
\hline \$D\$12 & E2 Flow & 0 & 100 \\
\hline$\$ D \$ 13$ & t Flow & 0 & 400 \\
\hline \$D\$14 & t Flow & 0 & 600 \\
\hline
\end{tabular}


The optimal scheduling is obtained by considering the optimal flows obtained in Step 1 and Step 2, which can be represented as in Table 6.

Table 6: Optimal scheduling for Example 1.

\begin{tabular}{|l|c|c|}
\hline Optimal Schedules & Opt. Flow1 & Opt.Flow2 \\
\hline Product s1 (Priority/Normal) & 600 & 200 \\
\hline Product s2 (Priority/Normal) & 500 & 300 \\
\hline Product s3 (Priority/Normal) & 300 & 500 \\
\hline Machine 1 & 400 & 0 \\
\hline Machine 2 & 200 & 200 \\
\hline Machine 1 & 400 & 0 \\
\hline Machine 2 & 100 & 300 \\
\hline Machine 1 & 0 & 400 \\
\hline Machine 2 & 300 & 100 \\
\hline Machine 1 Total & 800 & 400 \\
\hline Machine 2 Total & 600 & 600 \\
\hline
\end{tabular}

The optimal flows along the arcs $\left(\mathrm{s}, \mathrm{S}_{\mathrm{k}}\right)$ provides the optimal scheduling for the lathes 1 and 2 and for the products 1,2 and 3 respectively. In other words, $f^{*}=(600,200,500,300,300,500)$ for the $\operatorname{arcs}\left(\mathrm{s}, \mathrm{S}_{\mathrm{k}}\right)$.

Thus, the optimal quantities to be supplied to the priority and normal customers and the corresponding unfulfilled demands (as shown in the brackets) are as in Table 7. Observe that there are 200 units each of unfulfilled quantities for normal customer for the products $S_{1}$ and $S_{3}$. These quantities could be rescheduled with customer's concurrence.

Table 7: Optimal supply quantities and the unfulfilled demands

\begin{tabular}{|llll|}
\hline Order Type/Product & $\mathbf{S}_{\mathbf{1}}$ & $\mathbf{S}_{\mathbf{2}}$ & $\mathbf{S}_{\mathbf{3}}$ \\
\hline Priority & $\mathbf{6 0 0}$ & $\mathbf{5 0 0}$ & $\mathbf{3 0 0}$ \\
& $(\mathbf{0})$ & $\mathbf{( 0 )}$ & $(\mathbf{0})$ \\
Normal & $\mathbf{2 0 0}$ & $\mathbf{3 0 0}$ & $\mathbf{5 0 0}$ \\
\hline & $(\mathbf{2 0 0}$ & $(\mathbf{0})$ & $(\mathbf{2 0 0})$ \\
\hline
\end{tabular}

The capacities, scheduled/utilized capacities and the corresponding spare capacity available for the two lathes are shown in Table 8.

Table 8: Machine utilization and the spare capacities available for Example 1.

\begin{tabular}{|clcc|}
\hline & & & \\
Machine & Capacity & Scheduled & Spare capacity available \\
\hline $\mathbf{E}_{1}$ & 1200 & 1200 & 0 \\
$\mathbf{E}_{2}$ & 1200 & 1200 & 0 \\
\hline
\end{tabular}

It can be observed that, if the capacity exceeds the scheduled quantity, the difference provides the available spare capacity for each machine.

\section{Example 2: 3 Machines and 5 Products (Scheduling when order books are not full)}

Consider a workshop having three lathes $E_{1}, E_{2}$ and $E_{3}$ which are being used for manufacturing five types of roller sets $S_{1}$ to $S_{5}$. Let the machine capacities be as in Table 9 . 
Table 9: Machine capacities for lathes in Example 2.

\begin{tabular}{|llllll|}
\hline Machine / Product & $\mathbf{s 1}$ & $\mathbf{s 2}$ & $\mathbf{s 3}$ & $\mathbf{s 4}$ & $\mathbf{s 5}$ \\
\hline Lathe 1 & 250 & 100 & 100 & 200 & 250 \\
\hline Lathe 2 & 50 & 100 & 200 & 200 & 250 \\
\hline Lathe 3 & 100 & 100 & 150 & 150 & 300 \\
\hline
\end{tabular}

Consider the order position for priority orders and normal orders for the five roller sets $S_{1}$ to $S_{5}$ to be as shown in Table 10.

Table 10: Order position and priorities for Example 2.

\begin{tabular}{|lccccc|}
\hline Order Type/Product & s1 & s2 & s3 & s4 & s5 \\
\hline Priority & 200 & 100 & 50 & 300 & 150 \\
Normal & 100 & 200 & 150 & 50 & 400 \\
\hline
\end{tabular}

The optimal scheduling to the problem, using excel solver will be as in Table 11.

Table 11: Optimal scheduling for Example 2.

\begin{tabular}{|l|c|c|}
\hline Optimal Schedules & Opt. Flow1 & Opt.Flow2 \\
\hline Product s1 (Priority/Normal) & 200 & 100 \\
\hline Product s2 (Priority/Normal) & 100 & 200 \\
\hline Product s3 (Priority/Normal) & 50 & 150 \\
\hline Product s4 (Priority/Normal) & 300 & 50 \\
\hline Product s5 (Priority/Normal) & 150 & 400 \\
\hline Machine 1 & 100 & 100 \\
\hline Machine 2 & 0 & 0 \\
\hline Machine 3 & 100 & 0 \\
\hline Machine 1 & 100 & 0 \\
\hline Machine 2 & 0 & 100 \\
\hline Machine 3 & 0 & 100 \\
\hline Machine 1 & 50 & 50 \\
\hline Machine 2 & 0 & 100 \\
\hline Machine 3 & 0 & 0 \\
\hline Machine 1 & 0 & 50 \\
\hline Machine 2 & 150 & 0 \\
\hline Machine 3 & 150 & 0 \\
\hline Machine 1 & 0 & 0 \\
\hline Machine 2 & 0 & 250 \\
\hline Machine 3 & 150 & 150 \\
\hline Machine 1 Total & 250 & 200 \\
\hline Machine 2 Total & 150 & 450 \\
\hline Machine 3 Total & 400 & 250 \\
\hline
\end{tabular}

The optimal flows along the arcs $\left(\mathrm{s}, \mathrm{S}_{\mathrm{k}}\right)$ provides the optimal scheduling for the lathes 1,2 and 3 and for the products 1 to 5 respectively. In other words, $f^{*}=(200,100,100,200,50,150,300,50,150,400)$ for the $\operatorname{arcs}\left(\mathrm{s}, \mathrm{S}_{\mathrm{k}}\right)$.

Thus, the optimal quantities to be supplied to the priority and normal customers satisfy the ordered quantities, as shown in Table 10. 
The capacities, scheduled/utilized capacities and the corresponding spare capacity available for the three machines are shown in Table 12.

Table 12: Equipment utilization and the spare capacities available for Example 2.

\begin{tabular}{|cccc|}
\hline Machine & Capacity & Scheduled & Spare capacity available \\
\hline$E_{1}$ & 900 & 450 & 450 \\
$E_{2}$ & 800 & 600 & 200 \\
$E_{3}$ & 800 & 650 & 150 \\
\hline
\end{tabular}

\section{Conclusion}

In this paper, a working implementation of the excel solver for scheduling the MAN developed by Bokkasam (2016) is presented. The excel has been validated with results obtained and we can now solve large problems involving many machines and products. The methodology of the system described above is in general applicable to all single-stage, multi-item compatible production processes where the process can handle different types of products. Depending on the layout and process flow of the plant, a tailor-made production planning and scheduling system can be formulated using the suitable MAN and the excel solver application. In future, the managers will be able to use this technique for obtaining the results immediately for scaled-up scenarios.

\section{Acknowledgement}

This paper is supported by the Deanship of Graduate Studies and Research at Dar Al Uloom University, Riyadh.

\section{References}

Bokkasam Sasidhar (2016) Multiple Arc Network Model for Scheduling in a Single-stage, Multi-item Compatible Process. International Review of Management and Business Research, 5(3), 1223-1231.

Burkard, R. E. \& Hatzl, J. (2005) Review, Extensions and Computational Comparison of MILP Formulations for Scheduling of Batch Processes. Comput. Chem. Eng. 29: 1752-1769.

Floudas, C. A. \& Lin, X. (2004) Continuous-Time versus Discrete-Time Approaches for Scheduling of Chemical Processes: A Review. Comput. Chem. Eng. 28: 2109-2129.

Ford, L.R. \& Fulkerson, D.R. (2010) Flows in Networks. Princeton University Press. Princeton, NJ.

George C. Hadjinicola \& Andreas C. Soteriou (2003) 'Reducing the cost of defects in multistage production systems: A budget allocation perspective', European Journal of Operational Research 145(3): 621.

Gunter Schmidt (1992) 'A Decision Support System for Production Scheduling', Journal of Decision Systems 1 (2-3): 243-260.

Gunter Schmidt (1996) 'Modelling Production Scheduling Systems', International Journal of Production Economics 46-47: 109-118.

Kallrath, J. (2002) Planning and Scheduling in the Process Industry, OR Spectrum 24: 219-250.

Klaus Ecker, Jeet Gupta \& Gunter Schmidt. 1997. 'A Framework for Decision Support Systems for Scheduling Problems', European Journal of Operational Research 101(3): 452-462.

Maged M. Dessouky \& Brian A. Kijowski (1997). Production scheduling of single-stage multi-product batch chemical processes with fixed batch sizes, IIE Transactions, 29(5): 399-408.

Mendez C. A., Cerda'J., Grossmann I. E., Harjunkoski I. \& Fahl, M. (2006) State of-the-Art Review of Optimization Methods for Short-Term Scheduling of Batch Processes. Comput. Chem. Eng. 30: 913946.

Pan M., Li X. \& Qian, Y. (2009) Continuous-Time Approaches for Short-Term Scheduling of Network Batch Processes: Small-Scale and Medium-Scale Problems. Chem. Eng. Res. Des. 87: 1037-1058. 
Pinto, J. M. \& Grossmann, I. E. (1998) Assignment \& Sequencing Models for the Scheduling of Process Systems. Ann. Oper. Res. (81): 433-466.

Pugazhendhi, S., Thiagarajan, S., Rajendran, C. \& Anantharaman, N. (2003) 'Performance enhancement by using non-permutation schedules in floline-based manufacturing systems', Computers \& Industrial Engineering 44(1): 133.

Ridvan Berber, Mehmet Yuceer \& Zafer Ozdemir (2007). Automatic generation of production scheduling models in single stage multi-product batch plants: Some examples, Mathematical and Computer Modelling, 46(1-2): 69-79.

Saksena, J.P. (1982) Applications of O.R. Techniques -3. Decision Networks with Managerial Applications. National Productivity Council, New Delhi, India.

Saksena, J.P. (1985) 'Applications of decision networks', Journal of Operational Research 19: 41-44.

Sasidhar, B. \& Achary, K.K. (1991) 'A multiple arc network model of production planning in a steel mill', International Journal of Production Economics, 22: 195-202.

Shan Feng, Ling Li, Ling Cen \& Jingping Huang (2003) 'Using MLP networks to design a production scheduling system', Computers \& Operations Research 30(6): 821

Shashank Garg, D. Krishna Sundar \& K. Ravi Kumar (2012). A periodic tabular policy for scheduling of a single stage production-inventory system, Computers and Industrial Engineering, 62 (1): 21-28.

Shiqiang Liu \& Ong H.L. (2002) 'A comparative study of algorithms for the flowshop scheduling problem', Asia Pacific Journal of Operational Research, 19(2): 205-222.

Songsong Liu, Jose M. Pinto, \& Lazaros G. Papageorgiou (2010). Single-Stage Scheduling of Multiproduct Batch Plants: An Edible-Oil Deodorizer Case Study. Ind. Eng. Chem. Res. 49, 8657-8669.

Steven Hackman, German Riano, Richard Serfozo, Szu Hui Ng, Peter Lendermann \& Lai Peng Chan (2002) A stochastic production planning model. Technical Report. The Logistics Institute, Georgia Tech, and The Logistics Institute - Asia Pacific, National Univerity of Singapore.
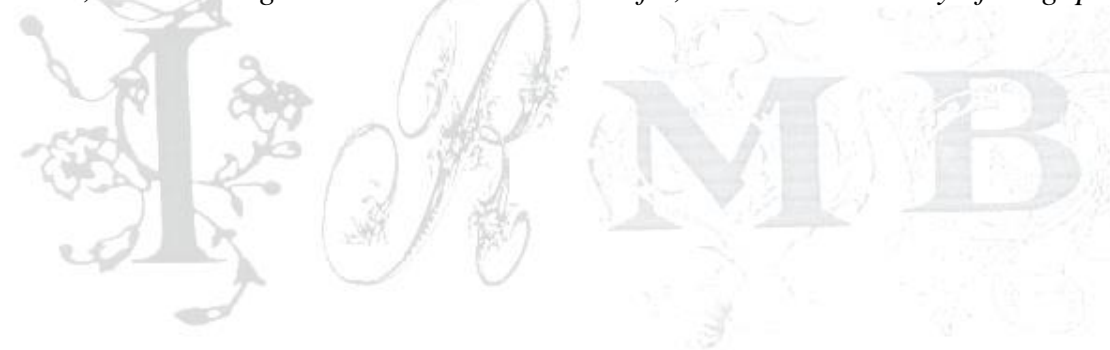